\title{
LA CONSTRUCCIÓN SIMBÓLICA DE LA GEOGRAFÍA JUDEO-GAY ${ }^{1}$
}

\author{
Damián Setton
}

\section{INTRODUCCIÓN}

Las últimas décadas del siglo XX han sido testigos de un proceso de rearticulación de los universos discursivos que atraviesan el espacio social judeo-argentino. Así, narrativas que habían sido centrales en la construcción de lo judío se ven desafiadas por nuevas construcciones de sentido que visibilizan otras dimensiones de identificación entre los judíos. Si en la década del sesenta la narrativa sionista había logrado desplazar de las organizaciones comunitarias centrales a su contrincante "progresista" (Bell, 2003; Svarch, 2005), esta misma narrativa comienza a ser desafiada en los años ochenta y noventa. Se trata de un proceso de reconfiguración del espacio de lo visible que pone en escena, institucionaliza y coloca en una trama de conflicto por su legitimación, aunque bajo una configuración diferente del diferencial de poder, a figuras de lo judío marginadas del relato sionis-

1 En el período que va desde la escritura de este artículo hasta el momento de su publicación han pasado muchas cosas. Algunos de nuestros informantes ya no ocupan los puestos institucionales aquí señalados. Además, en 2016 se concretó la primera boda, bajo las leyes judías, de dos personas del mismo sexo, uniendo en matrimonio a Romina Charur (actual Presidenta de JAG) y Victoria Escobar (Secretaria General de JAG). Sepan perdonar los lectores las afirmaciones algo desactualizadas del mismo. 
ta. Entre estas figuras, la emergencia de la problemática judeo-gay ${ }^{2}$ es tributaria del surgimiento de las instancias que politizarían la relación entre homosexualidad, sociedad y Estado dando nacimiento a la cuestión gay (Meccia, 2006). Es en la década del ochenta, con el retorno de la democracia, que dicha cuestión surge en la Argentina en el marco de un creciente activismo que se plantea el objetivo de desprivatizar las relaciones sexuales homosexuales y politizar la homosexualidad fundando distintas organizaciones como la Comunidad Homosexual Argentina (CHA) en 1984, Gays por los Derechos Civiles (GDC) en 1991, la Sociedad de la Integración Gay-Lésbica Argentina (SIGLA) en 1992, así como organizaciones religiosas como la filial argentina de la Iglesia de la Comunidad Metropolitana, fundada en 1968 en Los Ángeles e implantada en Buenos Aires en 1987 (Meccia, 2006: 53-54 y 155-159).

Será con el comienzo del siglo XXI que lo judeo-gay, en la Argentina, se proyectará en tanto problemática legítima a través de las prácticas de activistas insertos en tramas organizacionales. En este artículo nos proponemos, como objetivo, analizar la construcción de una problemática, el proceso por el cual un grupo de actores sociales construye una definición de la realidad y se propone instalarla como parte del sentido común en el interior de un determinado grupo humano. Como veremos, nuestro caso nos permitirá analizar el papel que, en ese proceso, juega el establecimiento de una red de relaciones transnacionales. La inserción en esa trama de relaciones transnacionales es parte de un proceso más amplio de internalización, por parte de los actores sociales, de una determinada representación del espacio. Sostenemos aquí que la geografía judeo-gay es experimentada como un espacio transnacional donde ciertas regiones ocupan lugares centrales mientras que otras son pensadas como periféricas. No se trata de una geografía imaginaria que borra las distinciones entre los Estados nacionales, sino que, por el contrario, las actualiza. En este sentido, el activista judeo-gay se percibe a sí mismo inmerso en un espacio transnacional atravesado por diferencias entre los Estados nacionales, los cuales son percibidos en tanto configuraciones culturales categorizadas de acuerdo a lo que se define como el grado de avance en relación a la temática judeo-gay. Esta percepción, cabe señalar, remite a los motivos que forman parte de un relato judeo-gay,

2 Nos referiremos en este trabajo al término gay, antes que LGBT (lésbico, gay, bisexual y transgénero) o a otros términos que den cuenta de la amplitud de las sexualidades no homosexuales. Esto se debe a que la problemática que se ha hecho visible remite a las articulaciones entre lo judío y lo gay, donde los principales protagonistas y activistas son hombres. Las judías lesbianas no han tenido el mismo grado de visibilización e institucionalización, mucho menos las travestis. 
sin suponer necesariamente una concepción del mundo aplicable a cualquier problemática.

\section{LA DIMENSIÓN TRANSNACIONAL EN LA CONSTITUCIÓN DEL ESPACIO SOCIAL JUDEO-ARGENTINO}

El espacio social judeo-argentino ha sido, históricamente, moldeado en la interpenetración de tramas nacionales y transnacionales. La población judía de la Argentina se configura a través de procesos de inmigración cuyo carácter masivo datan de fines de la década de 1880, cuando el aluvión de inmigrantes de Europa del este se incorpora a un espacio que ya venía siendo poblado por judíos europeos occidentales que habían dado forma a la Congregación Israelita de la República Argentina, primera organización del judaísmo argentino. La población judía se fue articulando sobre la base de diferenciaciones que remitían a los contextos de origen, reproduciendo marcos de identificación en función de países y ciudades de proveniencia. En este sentido, la implantación en el interior de un territorio que sus élites políticas habían imaginado como contenedor de una población destinada a la argentinización y a la fundición en un crisol de razas, no implicó el abandono de las relaciones transnacionales de la población migrante. Este tipo de relaciones fueron concebidas en un clima de búsqueda de integración a la nación argentina, poniéndose en circulación una serie de discursos que daban cuenta de la compatibilidad de ambas dimensiones identitarias, la nacional y la transnacional.

El proceso de argentinización supuso la rearticulación de los marcos de identificación basados en los lugares de origen. Las organizaciones con pretensiones comunitarizantes comenzaron a incluir en un mismo espacio a judíos con distintos orígenes geográficos. A la vez, las ciudades y países de origen fueron perdiendo peso en tanto factor pertinente en el establecimiento de relaciones interpersonales, aunque sin perder completa relevancia. Estos marcos de identificación se articularon con marcos religiosos y políticos dando lugar a diversas combinaciones. A la vez, la construcción de una matriz comunitaria (kehilatí) institucionalizada en la Asociación Mutual Israelita Argentina (AMIA), en tanto marco que agrupaba a la judeidad ashkenazi $\hat{i}^{3}$, proyectó un imaginario que articulaba un ideal de integración a la nación argentina con el mantenimiento de relaciones transnacionales.

Los judíos que poblaron el territorio argentino provenían de lugares disímiles como Europa central, Europa oriental, el Medio Oriente y el norte de África. Las identificaciones con los lugares de origen res-

3 Por ashkenazím entendemos a los judíos provenientes de Europa y a sus descendientes. 
pondieron a diversas dinámicas. En parte, provenir de determinado lugar comportaba cargar con imágenes y estereotipos que se actualizaban en la interacción dentro del espacio social judeo-argentino. Los procesos de identificación dependían del entramado de representaciones que portaban los inmigrantes, así como de proyectos identitarios que se articularon a través de la proyección de discursos, siendo la prensa comunitaria un canal de trasmisión de dichos proyectos. Resulta interesante el análisis de casos como el de los judíos provenientes de Siria quienes, con el desarrollo del conflicto en Medio Oriente, comenzaron a identificarse con el sionismo y a perder su identificación con el país de origen, así como con la población inmigrante no judía del mismo país. El caso de la inmigración de los países de habla alemana da cuenta de varios procesos, entre ellos el de sectores que, a medida que los crímenes de nazismo se fueron haciendo públicos, comenzaron a articularse en torno a proyectos identitarios que renegaban de la identificación con lo germano en beneficio de una identificación con lo judío mediada por la identificación con el sionismo y el Estado de Israel (Bankier, 1989; Friedmann, 2011).

Los universos de sentido que han estado en la base de las diferenciaciones internas de la población judía, así como la dinámica de conflictos, posicionamientos y relaciones cambiantes de poder, han respondido a tramas y coyunturas externas cuyas dinámicas, a veces, escapaban al control de los actores locales. Es así como la colonización agrícola judía no puede pensarse por fuera de la influencia de factores transnacionales vinculados a la dirección desde París del proceso migratorio. Dicha colonización supuso la construcción de un espacio que condensaba referencias propias de diversos contextos nacionales y culturales:

[s]us identidades tradicionales religiosas traídas de las provincias rusas sureñas de Kherson, Besarabia y Tavria fueron reconstruidas en la periferia rural de provincias argentinas, a la par que se introducían las técnicas de trabajo y gestión de Europa occidental. (Senkman, 2007: 419)

La colonia fue un espacio forjado en la interrelación con Europa, efectivizada tanto en la dirección institucional francesa como en la circulación de visitantes provenientes de Europa del este. A la vez, se concibió como espacio en el interior del cual se realizaría el proceso de argentinización de los inmigrantes.

En cuanto a la formación de un campo político judío, no es posible comprender los procesos implicados obviando la referencia al modo en que los inmigrantes actualizaron, en el escenario local, un conjunto de referencias que traían desde sus lugares de origen (anar- 
quismo, comunismo, socialismo, sionismo). Ese mismo campo político fue reconfigurándose en torno a procesos que superaban el ámbito local, como muestra el caso de la fundación del Idisher Cultur Farband (Federación de Entidades Culturales Judías) (ICUF) argentino en 1941, que consistió en la aplicación a nivel local de las decisiones establecidas en el congreso de París de 1937. A la vez, el mismo desarrollo del comunismo judeo-argentino respondió a tensiones entre la identidad nacional y el internacionalismo, que fueron dando como resultado diferentes configuraciones identitarias de acuerdo al contexto temporal (Visacovsky, 2015).

La construcción de un espacio religioso en el interior del más vasto espacio judío respondió a movimientos transfronterizos que no solamente trajeron contingentes de inmigrantes sino también activistas que, en algunos casos afiliados directamente a centros ubicados en otros países, otras veces sin responder a ellos, contribuyeron a configurar las relaciones de lo religioso con lo judío en la Argentina. Una historia de los liderazgos religiosos no podría dejar de lado el hecho de que el fundador del Movimiento Conservador en la Argentina, Marshall Meyer, hubiera llegado desde los Estados Unidos ${ }^{4}$, mismo país de procedencia de Dov Ber Baumgarten, figura sobre la cual se fue configurando la rama argentina del movimiento ortodoxo Jabad Lubavitch $^{5}$, o que tanto los rabinos Oppenheimer y Scheebar, pilares, cada uno a su manera, del proceso de revitalización de la ortodoxia, hayan provenido el primero de Holanda y el segundo de Siria ${ }^{6}$. A la vez, la historia institucional judía está marcada por la fundación del Estado de Israel, así como por su propia dinámica política. Los acontecimientos relativos a la judeidad en la Unión Soviética y el bloque de países comunistas impactaron en la configuración del diferencial de poder entre los diferentes movimientos políticos que se disputaron los espacios centrales de poder institucional. La centralidad que adquirió el sionismo en la década del sesenta (Elkin, 1986) se debe, en parte, al debilitamiento de los sectores identificados con la Unión Soviética, consecuencia, a la vez, de las persecuciones sufridas por los judíos en el bloque comunista. La actual crisis del sionismo se relaciona con la revitalización de la ortodoxia que, como se dijo, es tributaria de procesos a escala transnacional, no solo debido a la migración de líderes sino a la articulación que los sectores ortodoxos en la Argentina

4 Sobre el movimiento conservador en la Argentina y la figura de Marshall Meyer, ver Fainstein, 2006, Weil, 1988.

5 Sobre el movimiento Jabad Lubavitch, ver Setton, 2011.

6 Sobre el rabino Scheebar, ver Brauner, 2009. 
pueden hacer con centros de estudios religiosos de otros países como, principalmente, los Estados Unidos e Israel.

La experiencia identitaria judía no puede comprenderse sin tener en cuenta cómo se fue construyendo el conocimiento respecto a lo que ocurría fuera de la Argentina, cómo fue recibida la información, cómo fue interpretada y cómo circuló. Cómo en esos procesos se fue construyendo una geografía simbólica, una representación del mundo basada en la diferenciación entre zonas, entre espacios de peligro y de refugio, del nosotros y el ellos, espacios del enemigo y del aliado, espacios que actualizaban la memoria de la tragedia y aquellos que despertaban esperanza, orgullo y nuevos temores.

La referencia a la geografía imaginaria nos coloca en el debate acerca del concepto de diáspora y de las relaciones centro-periferia entre la "patria originaria (Homeland)" y el país habitado. El debate entre Safran y Clifford pone de manifiesto las divergencias respecto a la existencia de un centro articulador de procesos de diasporización en el judaísmo. Mientras Safran sostiene que "más que en otras diásporas, la identidad del judío parece definirse, cada vez más, en términos de su relación con Israel" (2005: 53), Clifford argumenta que

las conexiones transnacionales que vinculan a las diásporas no necesitan articularse primariamente a través de una patria originaria, real o simbólica - al menos no en el grado que Safran insinúa-. Conexiones laterales y descentradas pueden ser tan importantes como aquellas formadas alrededor de una teleología de origen/retorno. (1994: 306, traducción nuestra)

Ciertamente, la política israelí tendió, al menos hasta los años noventa, a la definición de Israel como centro articulador de la existencia judía, fomentando la representación de una relación centro-periferia (Sheffer, 2005). Sin embargo, el sionismo nunca implicó la negación completa de la diáspora. Al imperativo de migración se sumó una dimensión identitaria según la cual el sionismo fue pensado como un medio para fortalecer a las mismas comunidades diaspóricas. El sionismo, al proponer un referente de identificación hegemónico, se asumía como el garante de la continuidad de la vida judía diaspórica (Bokser Liwerant, 2007, 2009). En este sentido, sostiene Bokser Liwerant, la creación del Estado de Israel produjo una tensión entre el proyecto nacional y el estímulo al desarrollo de comunidades judías en la diáspora. El sionismo se encontró en una tensión entre una dimensión negadora de la diáspora y una dimensión identitaria que fortalecía la misma existencia diaspórica. Esto era posible en la medida en que Israel apareciera ante los judíos tanto como centro material, para quienes emigraban a él, como espiritual y cultural para los que no emigraban. 
En otro trabajo hemos dado cuenta de cómo la narrativa judeogay forma parte de procesos de diasporización (Setton, 2015). Si bien el activismo judeo-gay en América Latina se construye en función de identificaciones múltiple que incluyen el sionismo y la identidad nacional referida al país habitado, los estudios sobre estos casos nos permiten profundizar en el problema de las relaciones centro-periferia, contribuyendo así al desarrollo del concepto de diáspora.

\section{LA ORGANIZACIÓN DE LO JUDEO-GAY}

El proceso de organización de lo judeo-gay en la Argentina remite a dos iniciativas ${ }^{7}$. Keshet (en hebreo: Arcoíris), fundada por Germán Vaisman a mediados del 2004, se proponía como un sector destinado al esclarecimiento y la transformación de la comunidad judía en función de una mayor aceptación de su componente gay. Por otro lado, el grupo JAG (en hebreo: celebración; también, iniciales de Judíos Argentinos Gays) había surgido con el fin de agrupar judíos homosexuales ${ }^{8}$ que sentían que su condición sexual los desplazaba del ámbito comunitario. Mientras Keshet representaba una dimensión política de la problemática judeo-gay, JAG parecía reproducir una dimensión social vinculada al encuentro y a la formación de un espacio de contención. En entrevistas recientes, activistas de JAG describen a Keshet como una organización que "salía a tocar puertas", mientras que el proyecto de JAG tendía a "cuidarnos a nosotros mismos, porque nunca nos van a entender y nunca nos van a aceptar". De acuerdo a relatos de los propios protagonistas, las relaciones entre estas organizaciones estuvieron marcadas por una rivalidad basada en esta diferencia, situación que se perpetuó hasta el momento en que ambas se fusionaron en 2008. Un miembro de JAG relata los orígenes de este modo:

La fusión con Keshet fue dialogada, porque al principio hubo toda una cosa de enfrentamiento, medio patotera, "nosotros somos los intelectuales y políticos y ustedes son los huequitos que vienen a hacer actividades de nada, vienen a hacer nada, en realidad. Nosotros venimos con contenido", era como una cosa así, el enfrentamiento, para decirlo en dos palabras. Pero después nos pusimos a hablar y la verdad que la idea

7 Sobre los inicios de la institucionalización del movimiento judeo-gay fuera de la Argentina, ver Cooper, 1989.

8 Ciertamente, al entrevistar a sus miembros, estos señalan que el término gay en las iniciales del grupo da cuenta del colectivo completo de la diversidad sexual. No obstante, las lesbianas no han encontrado en JAG un espacio que las interpele (Correa: 2011: 46).

9 Luís Perelman en entrevista a Perelman, fundador de Shalom Amigos, y Gustavo Michaníe, actual miembro de JAG, realizada en enero de 2012. 
era que estuviéramos todos juntos, porque la idea no era estar enfrentados. (Entrevista a un miembro fundador de JAG, octubre de 2011)

La distinción entre un espacio percibido como "con contenido" y un espacio que se autodefinía como "social" reproducía dos tendencias que, en la década del noventa, disputaban espacios de poder en el espacio social judeo-argentino. En un contexto donde el sionismo parecía ver debilitada su posición, surgían sectores políticos centrados en los clubes y countries que disputaban a Avodá, la rama argentina del Partido Laborista israelí, el control de las instituciones centrales (Chab, 2001: 69-71; Melamed, 2000: 105-113). En el caso que estamos analizando, las posturas social y política confluyen cuando Keshet se disuelve formalmente y Germán Vaisman pasa a integrar la comisión directiva de JAG. El alcance de la dimensión política no puede determinarse en función de una serie de índices construidos por el investigador, sino que los actores involucrados van construyendo sus propias perspectivas acerca de la cuestión. Un análisis de estas construcciones muestra la falta de consenso en lo que respecta al alcance de JAG en tanto organización politizada.

JAG pasó por un proceso de institucionalización, de ser un grupo que se reunía en la casa de uno de sus miembros sin tener demasiado claro el objetivo a cumplir, a ser un espacio que establece relaciones con factores de percibido poder dentro del mundo judío y que, a nivel del Estado nacional, forma parte del INADI. Este proceso ha corrido en paralelo con la creciente visibilidad que sus miembros han ido adoptando, visibilidad que ellos mismos ejemplifican recordando cómo, en los inicios, solían dar entrevistas de espaldas. Esas entrevistas son parte de un pasado que es percibido como superado, al menos en lo concerniente a la exposición pública que algunos judíos gays han comenzado a reivindicar. Visibilidad que es parte de la que el movimiento gay en su conjunto viene teniendo desde el retorno de la democracia en 1983 (Meccia, 2006). No obstante, cabe señalar que la visibilidad es un concepto relacional que se construye en la comparación entre el presente y el pasado del movimiento, en la comparación con otros grupos y también en la comparación entre lo que cada actor percibe como la visibilidad concreta y la visibilidad esperada, entre lo que es y lo que debiera o podría ser. De ahí que diferentes actores involucrados en la dinámica judeo-gay evalúen de diferente manera el grado de visibilización que ha tenido JAG ante eventos determinados, así como a nivel general (Setton, 2014).

Lo interesante de la reconstrucción de los momentos fundadores que realizan los actores radica en que pone de manifiesto la tensión entre la doble dimensión de la experiencia judeo-gay. Por un lado, la 
dimensión política, por el otro, la dimensión social. Esta doble dimensión marca una tensión que se expresa de diferentes maneras. Lo social es percibido como un momento de la experiencia, pero teñido de un sesgo estigmatizable en tanto conduce a la autosegregación y la guetoización. Por otra parte, lo político es percibido como la expresión de cierto elitismo judío: los políticos contra los "huecos". Lo político como pretensión (también estigmatizable) del monopolio del sentido, en un contexto donde otras formas de sociabilidad pretenden erguirse como opciones legítimas que, a la vez que sientan la base de la reconfiguración del propio espacio político judío, se proyectan como opciones válidas para combatir el proceso de asimilación (Melamed, 2000: 105) ${ }^{10}$. El relato de los orígenes, al dar cuenta de la fusión entre Keshet y JAG, no solo da cuenta de un hecho, sino que expresa la voluntad de construir una simbiosis entre lo político y lo social en tanto dimensiones constitutivas del campo de conflicto en el interior del espacio social judeo-argentino.

El uso de las categorías "lo social" y "lo político" no surge del investigador, sino de los propios actores a través de las entrevistas realizadas. En este sentido, no son construcciones del investigador, sino que forman parte del sistema de categorías con la que los actores experimentan la realidad en la que están sumergidos. La experiencia de lo que ellos mismos hacen está atravesada por la disponibilidad de estas categorías, que, de alguna manera, integran el universo de sentido judaico. No es de extrañar que, en entrevistas y conversaciones informales con los actores, nos hayamos encontrado con el término hebreo peulá, el cual remite a una forma de socialización judía propia de niños y adolescentes basada en la realización de actividades recreativas (más allá de que puedan tener contenido político, religioso, o de otro tipo). La peulá reenvía a las actividades no politizadas de JAG, como los bingos o los shows, pero también a las actividades puertas adentro. Y nuevamente, la tensión entre el adentro y el afuera es constitutivo de las experiencias judías como puede verse en los debates que fueron surgiendo tras el atentado a la AMIA en 1994, donde se podían oír cuestionamientos a la presencia de las problemáticas de la comunidad judía en los medios masivos de comunicación. Esta tensión entre el adentro y el afuera es, a la vez, constitutiva de las experiencias institucionales e identitarias LGBT, como puede observarse en la metáfora del closet. Si los homosexuales, lesbianas, bisexuales, travestis, etc., hacen referencia a la salida del closet como parte de un relato identitario así como de una exi-

10 La mención a la asimilación es, sin duda, una base de construcción de legitimidad en el marco de una población que, desde sus instancias organizacionales, ha construido un discurso de matices apocalípticas respecto a este tema. 
gencia institucional, sectores del judaísmo construyen la experiencia de sí apelando a la metáfora del gueto. Los miembros de JAG se piensan a sí mismos recurriendo a esta tensión entre lo social y lo político, entre la guetoización y la visibilización. Si bien hay suficientes indicios que dan cuenta de una creciente visibilización, no deberíamos deducir la existencia de un proceso que conduce claramente y sin altibajos de una instancia de guetoización a una de visibilización. El gueto y la calle reclaman, ambos, sus "derechos" de pertenencia a un imaginario que impregna la visión que los actores tienen del mundo y de sí mismos. La potencia de dichas categorías no se anula en la acción de los actores. Así, más allá de la visibilización que los judíos gays han adquirido, no faltan quienes recurren al imaginario del gueto para definir la posición actual de los actores. No se trata de comparar estas representaciones con una supuesta realidad objetiva susceptible de medición científica, sino de observar las categorías que se encuentran en la base de la puesta en escena de diversos discursos. Así, el siguiente testimonio de un rabino vinculado a JAG se construye sobre la base de pensar a JAG como un sector menos visible de lo que podría llegar a ser:

A mí me dio la sensación de que JAG se quedó corto con el debate de la ley y todo eso. Esa noche yo estuve en [un programa de televisión] salí de ahí y me fui a la plaza, estaban todas las organizaciones. Me acuerdo de llamar, del celular, a los chicos de la Comisión Directiva de JAG, a decirles muchachos donde están. [Respondieron] "Está fresco, lo estamos viendo en la casa de alguno". [Respondí] 'Vénganse con la bandera, con la kipá, con lo que sea”'. (Entrevista realizada en 2010)

Por otro lado, otro testimonio da cuenta de lo contrario. Ante la pregunta por la modalidad de intervención en el contexto del debate sobre la ley de matrimonio igualitario, desde la presidencia de JAG se señala que:

Nosotros lo que empezamos a trabajar fue en el apoyo. JAG primero se vinculó justamente a personalidades del judaísmo [menciona los nombres de varios rabinos] y después también con referentes como Luis Grynwald, el ex presidente de AMIA, la gente del American JOINT. ¿Viste cuándo salió la carta esa de búsqueda de apoyo?, nosotros nos hemos movido para dar eso. Esto es lo que fue el año pasado. Este año se trabajó sobre lo que fue en el Senado, tuvimos una entrevista con una senadora de la provincia de Jujuy, Liliana Fellner, que le interesó ver el punto de vista de judíos gays. (Entrevista a Gustavo Michaníe realizada en 2010)

Este testimonio fue recogido de una entrevista realizada a un representante de JAG en la oficina desde la cual representa al movimiento. Es posible que el contexto de la entrevista haya contribuido a dar 
prioridad a los elementos que remiten al polo de la visibilidad antes que de la guetoización, pero lo cierto es que las acciones que señala se realizaron y que las mismas suponen, desde esta perspectiva, una acción tendiente a la visibilización, mientras que para otros pudieron no haber sido suficientes y, poniendo el énfasis en el polo de la guetoización, hayan recordado otros hechos.

\section{CIRCULACIONES TRANSNACIONALES Y CONSTRUCCIÓN DE LA PERCEPCIÓN DEL ESPACIO}

El análisis de las trayectorias de los activistas judíos gays nos permite observar cómo las circulaciones transnacionales fueron configurando una particular percepción del espacio. El conjunto de percepciones configura una geografía judeo-gay, es decir, un espacio significativo, impregnado de sentido, en el interior del cual los actores sociales actúan.

La trayectoria de Luís Perelman ${ }^{11}$ nos ofrece un ejemplo de lo afirmado. Perelman nació en México en 1962. Su trayectoria es la de un activista comunitario que, a través de su activismo, reproduce la dimensión judía de su complejo identitario a la vez que invisibiliza la dimensión gay. Las representaciones que tiene del espacio judío inhiben la proyección pública del componente homosexual de sí mismo. A los veintisiete años viaja a Israel, acontecimiento que define como su nacimiento. El término "nacimiento" da cuenta, en este discurso, del hecho de reconocerse en una identidad que ya no será ocultada. El viaje constituye un momento en la formación de la geografía judeogay, es decir, de una percepción del espacio por parte de los actores sociales que influye en sus prácticas activistas y en la redefinición de los diacríticos fundantes del activismo. Así, Perelman terminará siendo no solo un activista judío, sino judío y gay, colocando la dimensión gay en el espacio público del mismo modo que, antes, había colocado la dimensión judía. El hecho de poder observar cómo en Israel existían formas de sociabilidad fundadas en lo judío y lo gay le llevó a concebir la posibilidad de reproducir dichas sociabilidades en México. Estando en Israel, tocó a la puerta de la asociación de judíos gays, donde fue recibido y se le entregó el libro The Best Little Boy in the World, escrito por Andrew Tobias, un judío gay estadounidense que había firmado el libro bajo el seudónimo de John Reid en 1973:

11 Si bien el caso mexicano no constituye el eje de este trabajo, el relato de Perelman, fundador de la organización mexicana judeo-gay, nos permite dar cuenta de cómo las referencias presentes en la construcción de la geografía judeo-gay se extienden más allá del marco nacional analizado, de ahí su inclusión en este escrito. Sería interesante una mayor profundización acerca de los relatos de activistas de otros países de América Latina. Sobre el caso de Chile, ver Setton, 2015. 
Leí su historia y dije 'casi es la mía'. Todo lo que tuvo que pasar para salir de ese modelo de que tienes que ser el niño bueno solamente así, y atreverse, y con eso él me dio ese empujoncito para atreverme a hacer un poco más, ya me atreví a ir a un sauna. (Entrevista realizada en enero de 2012)

Es interesante analizar el papel que los relatos biográficos de terceros cumplen en la experiencia que los actores tienen de sí mismos. La circulación de estos relatos a través de los libros y películas como Trembling Before God, permiten a los actores representarse un espacio de experiencias compartidas. Se trata de relatos que circulan transnacionalmente y que permiten recrear identidades que luego se van a proyectar en el interior de espacios nacionales. En efecto, si la escala de configuración de la identidad es global, la de intervención mediante el activismo será, básicamente, nacional. Esto es así porque las organizaciones que los activistas encabezan se definen como organizaciones propias de un territorio nacional, participando en encuentros internacionales en tanto representantes de países específicos. Si bien conciben la causa judeo-gay como una causa transnacional, que afecta a los judíos LGBT más allá del país de residencia, la propuesta identitaria no niega las especificidades nacionales. Así, en la página web de la organización judeo-gay Shalom Amigos puede leerse: "Celebramos las tres facetas de nuestra identidad, es decir, judía, mexicana y gay”"12.

Los viajes suponen, para Perelman, el establecimiento de contactos personales y a nivel de las organizaciones, específicamente con el Congreso Mundial de Organizaciones Gays y Lesbianas Judías en los Estados Unidos (World Congress of Gay, Lesbian, Bisexual and Transgender Jews - Keshet Ga'avah [Arcoíris del orgullo]), la asistencia a reuniones organizadas por dicha organización y el posterior descubrimiento de que en México había ya un ambiente de judíos homosexuales formado por personas que mantenían una "doble vida", sin publicitar su condición homosexual. Ese núcleo previo constituye, para Perelman, una cadena de contactos que le permitirá ir conociendo a quienes terminarán fundando, en 1994, la primera organización de judíos gays en México, Shalom Amigos. De este modo, el mapa de la judeidad mexicana es transformado. A la vez, la comunidad judía de México pasa a ser experimentada como un espacio plausible para la recreación de una experiencia judeo-gay pública. La identidad con guión, judía y gay, comienza a ser plausible en México. En efecto, la militancia judeo-gay no pretende circunscribirse a un espacio nacional, sino incentivar a la transformación de diferentes espacios nacio-

12 Ver <http://shalomamigos.org.mx/qs.html>. 
nales y a la construcción de identidades con guión que abarquen lo judío, lo LGBT y la nacionalidad, sea la mexicana en el caso de Shalom Amigos, o la argentina en el caso de JAG.

El relato de Perelman permite observar cómo los actores van estructurando su percepción de la geografía judeo-gay y cómo se van imaginando un espacio con sentido. Israel y los Estados Unidos aparecen como centros de una experiencia identitaria donde la conjunción entre lo judío y lo gay estaría más desarrollada que en América Latina. Es preciso contactarse con organizaciones y personas de esos países para luego trasladar ciertos modelos de sociabilidad a los países latinoamericanos. En efecto, esta geografía proyecta una relación centro-periferia tributaria de procesos históricos más amplios, donde las comunidades judías de Israel y Estados Unidos, numéricamente superiores, asumen un lugar dominante por la disponibilidad de recursos ${ }^{13}$. Si observamos el devenir de los congresos del World Congress hasta 2010, 14 se realizaron en Estados Unidos, 3 en Israel, uno en Holanda, uno en Londres y uno en México ${ }^{14}$, mostrando la predominancia que adquieren los Estados Unidos en la formación de la geografía judeo-gay. En este sentido, la relación centroperiferia puede ser analizada desde dos perspectivas. De un lado, una perspectiva sustentada en técnicas de medición que habilitan producir afirmaciones basados en "hechos objetivos". Por el otro, una perspectiva que pone el acento en los imaginarios y representaciones de los actores sociales. Desde esta segunda perspectiva, el relato de Perelman permite ubicar los relatos de los miembros de JAG en un espacio latinoamericano donde América Latina es percibida, desde las categorías que estructuran el imaginario judeo-gay, como una periferia. De este modo, el análisis del relato de Perelman no se justifica solamente por la influencia que Shalom Amigos ha tenido en los judíos argentinos gays para formar su propia organización, sino que se trata de observar una experiencia de la geografía judeo-gay compartida por actores latinoamericanos donde sus propios países son narrados como periferias frente a los Estados Unidos e Israel.

El relato de otro miembro de $\mathrm{JAG}^{15}$ recupera esta geografía:

13 De acuerdo a Dujovne, "la inserción de la política judía argentina dentro de un marco más amplio implica tener presente, en primer lugar, la debilidad relativa de la colectividad en términos demográficos y económicos respecto a otros colectivos judíos de la diáspora en otros países, e incluso Israel, y, en segundo término, el hecho de ubicarse esta dentro de un país periférico en el orden político y económico internacional" (2006: 43).

14 Información recuperada de <http://www.glbtjews.org/article.php3?id_article $=121>$ acceso 26-10-2012.

15 Nos abstenemos de mencionar su nombre por pedido del entrevistado. 
Diego [Guinecín, miembro fundador de JAG] recibe una llamada de una persona de Estados Unidos, preguntándole a él si acá había un grupo de judíos gays, y Diego dice que no. Entonces Diego me llama y me cuenta esto. Nosotros siempre habíamos fantaseado con la idea de que hubiera un grupo. (Entrevista realizada en octubre de 2011)

La historia de la llamada de Norman, un judío gay norteamericano, forma parte del relato fundador de JAG. Precisamente, el relato toma la nacionalidad de Norman como un hecho significativo que se conjuga con la mayor edad que tenía respecto a los miembros de JAG y con el hecho de que hubiera salido del closet ya mucho tiempo antes.

Retomando los relatos biográficos, uno de los fundadores de JAG cuenta cómo su viaje a Miami, por motivos que no estaban relacionados con el activismo gay, constituyó un momento bisagra de su experiencia de sí mismo que, a la vez, repercutió en su constitución en tanto activista en la Argentina.

Yo siempre digo, que era como nacer a los veinte. Fue descubrir un mundo nuevo. Era la posibilidad de ver un mundo totalmente distinto. Tener la posibilidad de que todo lo que yo en realidad había creído y me habían enseñado y me habían mostrado, era totalmente distinto. Todo lo que yo creía, pensaba, hasta ese momento, era completamente diferente. Fue muy interesante. La mejor experiencia de mi vida, la mejor. (Entrevista realizada en octubre de 2011)

La ciudad de Miami aparece, en el relato, como un espacio cargado de significado. Expresa un momento bisagra de la trayectoria, aparece como un espacio de descubrimiento narrado de manera cercana a los relatos de conversión religiosa.

La trayectoria de Germán Vaisman permite indagar en las articulaciones entre lo transnacional como fundador de la experiencia judeo-gay y la inserción en una trama organizacional que atraviesa las fronteras de los Estados. El viaje de Germán a Boston en 2001 se enmarca en su trabajo comunitario en el interior de la comunidad judía. Allí trabaja en un refugio para mujeres latinas y en Keshet, una organización gay lésbica de educación y trabajo.

Y lo que hacíamos ahí, más que nada, trabajábamos con temas comunitarios internos gay lésbicos, pero más que nada es una herramienta para generar un cambio en la comunidad judía en general. Era como una estrategia de crear comunidad pero con el objetivo de generar cambios particulares. Entonces cuando volví quise como medio hacer lo mismo, [...] y fui a un congreso del JOINT que se hizo en Guatemala y ahí presenté un resumen, que es un texto que yo escribí, que en realidad es un texto mío pero que saqué cosas de distintos lugares como para generar 
una especie de situación de estado de qué es ser gay judío. Y le había puesto en ese momento "silencio exiliador", porque en realidad, había una opción constante que era exiliarse para poder... es decir, uno tenía que silenciarse o exiliarse. Esa era como la gran decisión de los judíos gays y lesbianas. Y bueno, lo que planteaba en esa charla era que en realidad no estaba bueno tener que tomar esa decisión. Y ese fue como el puntapié de mi activismo. (Entrevista realizada en octubre de 2010)

Boston aparece como un espacio que habilita un nuevo comienzo, el inicio de un activismo que se proyecta como núcleo del complejo identitario de Germán, del mismo modo que Perelman redefine su activismo judío en activismo judeo-gay a través de las experiencias que tiene fuera de su país. Aquí también encontramos una lógica de imitación. En efecto, los Estados Unidos son percibidos como una fuente de imitación ("cuando volví quise como medio hacer lo mismo"). La imitación implica una relación particular entre centro y periferia, donde el centro provee modelos a ser trasladados a la periferia. Sin embargo, no implica una actitud de imitador ciego, sino que el actor percibe cómo las diferencias entre el centro y la periferia condicionan el proceso de traspaso de una experiencia a un contexto diferente. Germán pretende importar un modelo de sociabilidad que le permite desarrollar su activismo mediante capacitaciones que irá tomando a los fines de construir un discurso militante. El análisis de las imágenes que los actores reproducen acerca de Boston da cuenta de cómo se estructura una geografía judeo-gay donde dicha ciudad se proyecta como un centro frente a una periferia donde el activismo estaría más apagado $^{16}$. En ese sentido, el actor es consciente de los límites de cualquier estrategia de imitación. El relato de un rabino que se ha vinculado con JAG nos permite observar la persistencia de un conjunto de imágenes que actualizan esta relación centro-periferia.

Yo estudié un año en Estados Unidos, en Boston, en un seminario [rabínico] muy liberal y además en una ciudad muy liberal. Cuando yo viví en Boston, ya estaba legalizado el matrimonio gay, tenía compañeros, ya no te hablo de compañeros homosexuales casados, yo tenía una compañera que era travesti... o un compañero [...] Cuando volví a la Argentina fue como un shock cultural bastante fuerte. (Entrevista realizada en 2010 )

En el relato de Gustavo Michaníe, actual miembro de JAG, se observa esta misma representación de los Estados Unidos. Allí, el Mo-

16 "Aplicar temas de Estados Unidos acá no sirve porque ahí la gente está hiperinvolucrada, hipercompenetrada con activar” (entrevista a Germán Vaisman, 2010). 
vimiento Conservador acepta a los rabinos y rabinas gays, mientras que en la Argentina ese mismo movimiento se mantiene reticente a dicha aceptación.

[Las organizaciones en Estados Unidos] tiene una convocatoria que no tenemos en ningún lugar del mundo, y eso es admirable y de eso tratamos de aprender. Hay comunidades que tienen rab y rabanit [...] que está aceptado por el Movimiento Masortí americano que sean rabinos LGBT, cosa que acá por ahí todavía nos falta un poquito. Estamos unos cuantos años atrás. (Entrevista realizada el 8 de octubre de 2010)

En este sentido, el movimiento se propone, como meta, aquello que denominan como la sinagoga inclusiva e igualitaria ${ }^{17}$, donde las parejas homosexuales puedan contraer matrimonio bajo la jupá, el palio nupcial, y que dicho matrimonio sea legitimado mediante la ketubá, es decir, que tenga valor legal para el judaísmo. Al hacer referencia a la sinagoga inclusiva, es hacia los Estados Unidos que los miembros de JAG vuelven a mirar. En efecto, es allí donde se realizan matrimonios homosexuales, a diferencia de las bendiciones que algunos rabinos han llevado a cabo en la Argentina, pero que carecen de status legal judío al no estar firmada la ketubá. A la vez, es allí donde homosexuales y lesbianas pueden ser ordenados como rabinos y rabinas. Nuevamente, el modelo centroperiferia se constituye en el eje a través del cual los activistas construyen una representación del espacio de lo judío-LGBT. A la vez, se percibe una distancia cultural entre una sociedad y la otra, donde

vos agarrás diez personas gays de allá y están armando una organización y te juntan los fondos, y acá vos tenés que ir a entregar un forro para la prevención y te miran mal, y si das una charla te dicen "otra vez la charla deprimente", entonces es como que tenemos un concepto distinto de lo que es la manera de ser americana. (Entrevista a Gustavo Michaníe realizada el 8 de octubre de 2010)

Finalmente, cabe señalar que la relación entre viajar al exterior y salir del closet o asumir una militancia judeo-gay no pretende aquí ser entendida en términos estadísticos. Más bien, pretende dar cuenta de un componente plausible de un relato judeo-gay. En efecto, la relación entre el viaje y la salida del closet es un motivo de un relato identitario, no solo desde el sujeto de la trayectoria, sino que también es posible comprobar la plausibilidad de este motivo en los relatos de quienes aseguran no haber salido del closet a causa de un viaje, pero agregan

17 Entrevista a Gustavo Michaníe en Haimovich (2011). 
que conocen a muchas personas a las que sí les ocurrió eso. En este sentido, más que una correlación estadística, lo que pretendemos es señalar la existencia de un motivo propio de un relato identitario que va más allá de las experiencias personales de cada actor.

\section{TRANSNACIONALIDAD Y ORGANIZACIÓN DE LO JUDÍO LGBT}

La organización del movimiento judeo-gay en la Argentina es tributaria de un conjunto de relaciones organizacionales a escala global que contribuyen a la capitalización simbólica del movimiento. El American Jewish Joint Distribution Commitee (JDC) es una organización destinada a fortalecer la existencia judía a través de la redistribución de fondos y la puesta en marcha de programas de ayuda social y capacitación. Las relaciones entre JAG y el JDC redundaron en la ampliación de las posibilidades de proyección del discurso jagueano más allá de las fronteras nacionales argentinas, en su visibilización transnacional que a la vez redunda en la ampliación de las posibilidades de creación de movimientos judeo-gays en otros países de América Latina. Así, los miembros de JAG comenzaron a participar de encuentros a escala regional latinoamericana ${ }^{18}$, así como a escala global, financiados en parte por el JDC, aunque en otros casos los fondos surgieron de los propios activistas. A la vez, la asesoría del JDC colaboró en el proceso de constitución de JAG en tanto organización, por ejemplo, en la gestión de la personería jurídica. La escala de acción del JDC es global, de ahí que los vínculos con el mismo incentiven un proceso de transnacionalización empujado desde el mismo JDC.

El significante "diversidad" instala un escenario en el interior del cual las relaciones entre JAG y el JDC se tornan plausibles. En el relato que hace de sí mismo ${ }^{19}$, el JDC se define como una organización que apuesta a la diversidad en el interior del mundo judío, que más que proponer un proyecto de fronterización, como podría ser el caso de movimientos políticos o religiosos dentro del espacio social judío, concibe a lo judío como un espacio donde conviven "todas" sus expresiones. Ese relato, estructurado sobre el referente "diversidad", abre una puerta de entrada al establecimiento de relaciones con JAG, cuyo postulado también se sustenta en dicho referente. En efecto, el JDC posee un área de "proyectos especiales" donde se trabajan cuestiones relacionadas con la diversidad, entre ellas los matrimonios mixtos entre judíos y no judíos.

18 JAG ha participado de los Encuentros de Dirigentes de Instituciones y Comunidades Judías Latinoamericanas y del Caribe, organizados por el JDC.

19 Reconstruimos este relato a través de una entrevista realizada a Mónica Cullucar, socióloga empleada del JDC, el 23 de febrero de 2012. 
Mónica Cullucar, socióloga empleada del JDC, recuerda cuando, en el contexto de la crisis de 2001-2002, un grupo de jóvenes gays se le acercó para reclamar que el tema de la homosexualidad fuera incorporado a las discusiones sobre diversidad. Así, los relatos del JDC y de JAG se articularon en el interior de un escenario configurado sobre "la diversidad" en tanto referente universal.

El proceso de organización del activismo judeo-gay va colocando a JAG en el interior del universo judeo-gay a escala global. Las organizaciones globales habilitan una serie de contactos a nivel personal entre activistas de diferentes países, lo que les permite fortalecer sus propias organizaciones en los contextos locales. Así, la membrecía en el World Congress permite el intercambio de información con otras organizaciones que comparten problemáticas similares. La circulación incluye también viajes a congresos donde se discuten una serie de temáticas relacionadas a lo LGBT, aunque no a lo judío. Los actores perciben esos viajes como una posibilidad de formarse, de adquirir experiencia, de observar cómo las mismas problemáticas son tratadas en otros contextos y recuperar esas experiencias para aplicar en el propio país. A la vez, reproduce el espacio de los mutuos reconocimientos, donde los actores sociales se sienten legitimados por otros y actualizan la evidencia de una particular construcción simbólica de la realidad.

Paralelamente, las relaciones con la Organización Sionista Mundial, a través del departamento de Hagshamá, abrieron un espacio para la proyección del discurso de los activistas de JAG.

Con ellos tuvimos un vínculo híper cercano, fueron los primeros que nos abrieron las puertas entre todos los ámbitos que ellos manejan y de todos los programas que ellos manejan. Inclusive yo he ido a Israel en dos oportunidades para capacitarme en liderazgo y en temática judía y temáticas israelíes, fui el primer representante oficialmente gay, desde la Argentina y desde el mundo, que fue invitado a Israel, cosa que me llenó de orgullo. (Entrevista a Diego Guinecín, octubre de 2011)

Las relaciones con el departamento de Hagshamá se fundan, en parte, por intermedio de relaciones personales entre los actores, como muestra el caso de que un miembro de dicho departamento y uno de JAG fuesen compañeros de danzas israelíes, amistad que habilitó encuentros a nivel institucional. De acuerdo al relato del representante del Departamento de Actividades para la Diáspora de la Organización Sionista Mundial, Enrique Grinberg, el departamento de Hagshamá estuvo en el origen de una estrategia de visibilización del colectivo judeo-gay, al cual publicitaron por intermedio de la Agenda Universitaria, una base de datos masiva utilizada como medio de difusión. 
A la vez, el departamento de Hagshamá se concentra en el trabajo con individuos que integran la franja etaria de 18 a 30 años. En este sentido, habilitó la producción de espacios de proyección del discurso jagueano entre jóvenes vinculados con las organizaciones judías. La potencialidad del departamento consiste en la posibilidad que tiene de reconfigurar las tramas de sentido movilizadas en el interior de las organizaciones comunitarias, incorporando y legitimando la figura del judío gay. De acuerdo a Grinberg, se trata de una estrategia de visibilización de una población hasta entonces marginada. Se trata de un proceso de construcción de la legitimidad que pasa por la organización de actividades donde los activistas de JAG son invitados a dar conferencias en espacios juveniles, donde se recurre a soportes de difusión para visibilizar la presencia de lo judío gay, donde se da apoyo económico y donde los representantes institucionales asisten a las actividades organizadas por JAG a fin de, mediante su presencia, actualizar la inserción del colectivo judío gay en el espacio organizacional judío. La revista Jutzpá, editada por el Departamento de Hagshamá y el Departamento de Juventud de la AMIA, publicó en su segundo número una nota a Gustavo Michaníe escrita por Erik Haimovich (2011) y una nota sobre organizaciones judeo-gays en Israel escrita por Yaniv Mazor (2011). Estas actividades suponen establecer una disputa de sentido con otras organizaciones que, como ciertos sectores ortodoxos en el gobierno de la AMIA, rechazan considerar lo judío gay como una forma legítima de judaísmo.

La relación con Hagshamá habilita la circulación trasnacional de los productos de una industria cultural centrada en lo judío LGBT. Como expresa Grinberg:

En Israel, la temática gay es una temática muy abierta, muy presente en la sociedad israelí. De hecho, hay varias películas de cine israelí que abordan la temática. Nosotros hemos ayudado a JAG muchas veces, y a Keshet en esa época, que existía también, con la traducción de películas para que participen en ciclos de cine gay acá de la Argentina. Ellos, como judíos, podían llevar una producción israelí sobre la temática a espacios que nosotros, desde las instituciones, o no podíamos llegar o no estamos cien por ciento interesados en llegar, porque no es nuestro mandato, pero que ellos lo veían como una cuestión de unir su identidad sexual con su identidad judía y su vínculo, también, con el Estado de Israel. (Entrevista realizada el 30 de marzo de 2012)

De este modo, se reproduce un espacio de circulación de significados a través de la circulación trasnacional de los productos de la industria cultural, espacio que se recrea en la actividad militante de los activistas vinculados con organizaciones trasnacionales. Paralelamente, 
la vinculación con el departamento de Hagshamá expresa y supone una vinculación con las problemáticas israelíes, habilitando formas de proyección en el espacio social judeo-argentino en función de su vinculación con Israel en tanto uno de los principales referentes de dicho espacio. La identificación con Israel como forma de proyección del activismo judeo-gay se expresó, a la vez, en la organización del ciclo de cine "Israel diverso", en el cual se proyectaron cuatro películas israelíes sobre temáticas que los actores consideraban vinculadas a la diversidad. Este ciclo fue llevado a cabo con apoyo de la Embajada de Israel en la Argentina y tuvo como motivo la celebración del sexagésimo quinto aniversario de la creación del Estado de Israel.

\section{CONCLUSIÓN}

El proceso de institucionalización de los judíos gays en la Argentina responde a una lógica que ha permeado diversas dinámicas identitarias e institucionales del judaísmo en este país. Como hemos podido observar, lo nacional y lo transnacional se han interpenetrado a lo largo de la historia de la población judeo-argentina. En este sentido, no es de extrañar que estas mismas dinámicas estén presentes en las reconfiguraciones del espacio social judeo-argentino que se proponen desde el activismo judeo-gay. Esta dinámica transnacional puede ser analizada desde dos perspectivas. Por un lado, tomando en cuenta las percepciones y representaciones de los actores sociales. Esto muestra cómo la geografía judeo-gay es una representación del espacio sustentada en la distinción centro-periferia, donde los Estados Unidos e Israel son representados como centro y América Latina como periferia. Habitar la geografía judeo-gay supone la internalización y reproducción de una serie de imaginarios relacionados a las escalas nacionales. Por otro lado, la dinámica transnacional se observa en las relaciones organizacionales que establecen los activistas judíos gays, relaciones que les permiten tornar visible una problemática.

\section{BIBLIOGRAFÍA}

Bankier, D. 1989 "Los exiliados alemanes y los refugiados judíos centroeuropeos en Argentina y Uruguay" en Estudios Migratorios Latinoamericanos, $\mathrm{N}^{\circ} 11$, abril, pp. 49-60.

Bell, L. 2003 "Bitter conquest: Zionist against progressive Jews and the making of post-war Jewish politics in Argentine" en Jewish History, $\mathrm{N}^{\circ} 17$, pp. 285-308.

Bokser Liwerant, J. 2007 "El lugar cambiante de Israel en la comunidad judía de México: centralidad y procesos de globalización" en Mendes-Flohr, P.; Assis, Y. T. y Senkman, L. 
(eds.) Identidades judías, modernidad y globalización (Buenos Aires: Lilmod/Universidad Hebrea de Jerusalem).

Bokser Liwerant, J. 2009 "Latin American Jews: A Transnational

Diaspora” en Ben Rafael, E.; Sternberg, Y.; Bokser Liwerant, J. y Gorny, Y. (eds.) Transnationalism. Diasporas and the Advent of a New (Dis)Order (Leiden, MA: Brill).

Brauner, S. 2009 Ortodoxia religiosa y pragmatismo político. Los judíos de origen sirio (Buenos Aires: Lumiere).

Chab, S. 2001 Entre la crisis y la esperanza: La comunidad judeoaegentina tras el atentado a la AMIA (Buenos Aires: Catálogos).

Clifford, J. 1994 “Diasporas” en Cultural Anthropology (Texas) Vol. 9, $\mathrm{N}^{\mathrm{o}}$ 3, pp. 302-338.

Cooper, A. 1989 "No longer invisible: Gay and lesbian Jews build a movement" en Journal of Homosexuality (Nueva York) Vol. 18, $\mathrm{N}^{\circ}$ 3-4, pp. 83-94.

Correa, M. 2011 "Religión y sexualidades. El caso de una organización judía GLBT (Gay, Lésbico, Bisexual y Trans.)", tesis de licenciatura (Buenos Aires).

Dujovne, A. 2006 “'Hay que ganar la calle judía’. Diáspora y política: Un análisis etnográfico de la izquierda judía en Argentina", tesis de maestría (Córdoba).

Elkin, J. 1986 "The Argentine Jewish community in changing times" en Jewish Social Studies (Indiana) Vol. 48, No 2, pp. 175-182.

Fainstein, D. 2006 "Secularización, profecía y liberación: la desprivatización de la religión en el pensamiento judío contemporáneo. Un estudio comparativo de Sociología histórica e historia intelectual", tesis de doctorado (México).

Friedmann, G. 2011 "Las identidades judeoalemanas: alemanes antinazis y judíos de habla alemana en Buenos Aires durante la segunda guerra mundial" en Kahan, E.; Schenquer, L.; Setton, D. y Dujovne, A. (comps.) Marginados y consagrados: Nuevos estudios sobre la vida judía en la Argentina (Buenos Aires: Lumiere).

Meccia, E. 2006 La cuestión gay: Un enfoque sociológico (Buenos Aires: Gran Aldea Editores).

Melamed, D. 2000 Los judíos y el menemismo (Buenos Aires: Sudamericana).

Safran, W. 2005 "The Jewish diaspora in a comparativa and theoretical perspective" en Israel studies (Indiana) Vol. 10, No 1 , primavera, pp. 36-60. 
Senkman, L. 2007 "Ser judío en Argentina: Las transformaciones de la identidad nacional" en Mendes-Flohr, P.; Assis, Y. T. y Senkman, L. (eds.) Identidades judías, modernidad y globalización (Buenos Aires: Lilmod/Universidad Hebrea de Jerusalem).

Setton, D. 2011 Revitalización de la ortodoxia judía y experiencias identitarias. Jabad Lubavitch en la Argentina (Saarbrucken: Editorial Académica Española).

Setton, D. 2014 "Entre la sociabilidad y la politización: La construcción de lo judeo-homosexual-gay en Buenos Aires" en Aposta (Barcelona) $\mathrm{N}^{\mathrm{o}}$ 62, julio, agosto y septiembre, pp. 1-31. Disponible en <http://www.apostadigital.com/revistav3/ hemeroteca/dsetton.pdf $>$.

Setton, D. 2015 "La construcción de identidades judías LGBT a través de prácticas diaspóricas: estudio sobre organizaciones judías LGBT en América Latina" en Sexualidad, Salud y Sociedad (Río de Janeiro) No 21, diciembre, pp. 25-52.

Sheffer, G. 2005 "Is the Jewish diaspora unique? Reflections on the diaspora's current situation" en Israel studies (Indiana) Vol. 10, $\mathrm{N}^{\circ}$ 1, primavera, pp. 1-35.

Svarch, A. 2005 "El comunista sobre el tejado. Historia de la militancia comunista en la calle judía (Buenos Aires: 19201950)", tesis de maestría (Buenos Aires).

Visakovsky, N. 2015 Argentinos, judíos y camaradas: tras la utopía socialista (Buenos Aires: Biblos).

Weil, A. 1988 Orígenes del judaísmo conservador en la Argentina (Buenos Aires: Ediciones del Seminario Rabínico Latinoamericano).

\section{FUENTES}

Haimovich, E. 2011 "Entrevista a Gustavo Michaníe" en Jutzpá (Buenos Aires) Año 1, No 2, diciembre, pp. 12-13.

Mazor, Y. 2011 "Judaísmo y homosexualidad. El caso de la organización de homosexuales religiosos" en Jutzpá (Buenos Aires) Año 1, $\mathrm{N}^{\circ}$ 2, diciembre, pp. 10-11. 